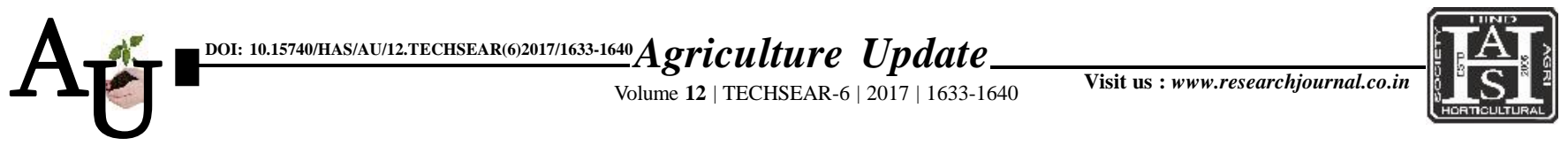

\title{
Research article: Genetic divergence in indigenous and exotic rice germplasm
}

\author{
AJAY KUMAR NAIK, S.P. SINGH, DILRUBA A. BANO AND KUDUKA \\ MADHUKAR
}

Article Chronicle : Received : 17.07.2017;

Accepted :

01.08 .2017

KeY WoRds:

Rice, $\mathrm{D}^{2}$ analysis, Multivariate analysis, GCV, PCV, Heritability, Genetic advance

Author for correspondence :

\section{KUDUKA}

MADHUKAR

Department of Genetics and Plant Breeding, Institute of Agricultural Sciences, Banaras Hindu University, VARANASI

(U.P.) INDIA

Email:kuduka_madhukar @yahoo.com
SUMMARY : Analysis of variance of 222 genotypes suggested that the genotypes differed significantly for all the 11 quantitative traits studied. Seedling height, 100-grain weight, grain yield per plant and number of effective tillers per plant showed higher estimates of genotypic co-efficient of variation. High heritability was recorded for most of the traits. High heritability coupled with high genetic advance was recorded for productive tillers per plant, 100-grain weight, grain yield per plant. Using Tocher's method, all the 222 genotypes were grouped into 15 clusters based on the relative magnitude of the $\mathrm{D}^{2}$ values. The intra-cluster distance was found minimum for cluster I and maximum for cluster VI while it was zero for VII, VIII, IX, X, XI, XII, XIII, XIV and XV as these clusters consisted of only single genotype. The maximum inter-cluster distance was recorded between cluster II and cluster IX. The cluster V recorded high mean values for plant height, panicle length and 100-seed weight. Cluster XIII recorded highest means for number of effective tillers per plant and yield per plant. Plant height, days to maturity, days to $50 \%$ flowering and leaf length contributed relatively maximum to genetic divergence.

How to cite this article : Naik, Ajay Kumar, Singh, S.P., Bano, Dilruba A. and Madhukar, Kuduka (2017). Genetic divergence in indigenous and exotic rice germplasm. Agric. Update, 12(TECHSEAR-6) : 1633-1640; DOI: 10.15740/HAS/AU/12. TECHSEAR(6)2017/1633-1640. 